NOTICE: This is the author's version of a work that was accepted for publication in Preventive Medicine. Changes resulting from the publishing process, such as peer review, editing, corrections, structural formatting and other quality control mechanisms may not be reflected in this document. Changes may have been made to this work since it was submitted for publication. A definitive version was subsequently published in Preventive Medicine: 1st Asia Pacific Clinical Epidemiology and Evidence Based Medicine Conference. Volume 57, Supplement, 2013, Pages S31-S33. http://doi.org/10.1016/j.ypmed.2012.11.009 


\section{Habitual physical activity reduces risk of ovarian cancer:}

\section{A case-control study in southern China}

Andy H. Lee ${ }^{\mathrm{a}}$, Dada Su ${ }^{\mathrm{a}}$, Maria Pasalich ${ }^{\mathrm{a}}$, Yut Lin Wong ${ }^{\mathrm{b}}$, Colin W. Binns ${ }^{\mathrm{a}}$

\footnotetext{
${ }^{\text {a }}$ School of Public Health, Curtin University, Perth, WA, Australia

${ }^{\mathrm{b}}$ Department of Social \& Preventive Medicine, University of Malaya, Kuala Lumpur, Malaysia
}

\section{Corresponding author:}

Professor Andy H. Lee

School of Public Health

Curtin Health Innovation Research Institute

Curtin University

GPO Box U 1987

Perth, WA, 6845

Australia

Phone: +61-8-92664180

Fax: +61-8-92662958

Email: Andy.Lee@curtin.edu.au

Short running title: Physical activity and ovarian cancer

Abstract word count $=199$ 


\title{
Habitual physical activity reduces risk of ovarian cancer: A case-control study in southern China
}

\begin{abstract}
Objective: To ascertain the relationship between habitual physical activity and the risk of ovarian cancer among southern Chinese women.
\end{abstract}

Method: A case-control study was conducted in Guangzhou, Guangdong Province, during 2006-2008. Information on physical activity exposure and lifestyle characteristics was obtained from 500 incident ovarian cancer patients and 500 hospital-based controls (mean age 59 years) using a validated and reliable questionnaire. Logistic regression analyses were performed to assess the association between physical activity levels and the ovarian cancer risk.

Results: The control subjects reported significantly longer duration of strenuous sports and moderate activity in daily life than the ovarian cancer patients. Increased engagements in such leisure time activities were associated with reduced cancer risks after adjustment for confounding factors. A significant inverse dose-response relationship was also found for total physical activity exposure, with adjusted odds ratio 0.49 (95\% confidence interval $0.35-0.68$ ) for women engaged in 23 or more metabolic equivalent tasks (MET)-hours per week relative to those less than 12 MET-hours per week.

Conclusion: The study provided evidence of an inverse association between habitual physical activity and the risk of ovarian cancer, which is important for the promotion and encouragement of leisure time exercise activities to prevent the disease.

Key words: Case-control study, China, ovarian cancer, physical activity

Abbreviation: MET, metabolic equivalent tasks 


\section{INTRODUCTION}

Ovarian cancer is the second most common gynaecological malignancy (Sankaranarayanan and Ferlay, 2006). Its incidence varies geographically, for example, the age-standardised rates in Europe, United States and Malaysia are 10.1, 8.8 and 7.5 per 100,000 females, respectively. In China, the incidence is relatively lower at 3.8 per 100,000 (Ferlay et al., 2010).

Established risk factors for ovarian cancer include early age of menarche, infertility, low parity and late age of menopause (Sueblinvong and Carney, 2009). Studies have also suggested that physical activity may play a role in its aetiology, but findings are scant with respect to Chinese women (Zhang et al., 2003; Zhang et al., 2004). Further investigation in this population is valuable, given the difference in incidence rates, the pathogenesis of the disease and the potential for physical activity as a modifiable risk factor.

\section{METHODS}

A hospital-based 1:1 case-control study was conducted in Guangzhou during 2006-2008. Subjects ( $<75$ years old) residing in Guangzhou for at least the past ten years were recruited from four public hospitals. Cases were incident epithelial ovarian cancer patients who had been histopathologically diagnosed within the past 12 months. Controls were recruited from inpatient wards of the Departments of ophthalmology, orthopedic, respiratory disease, gastroenterology and physiotherapy.

Potential cases were identified by searching the daily hospital census. To ensure complete ascertainment, all medical records and pathology reports were reviewed. Patients were excluded when ovarian cancer was histopathologically confirmed to be neither the primary nor final diagnosis. Of the total 504 cases consecutively recruited, 500 patients consented to be interviewed. Meanwhile, 512 eligible controls were identified, who were frequency matched to cases by age ( \pm 5 years). Exclusion criteria were (i) previous diagnosis of ovarian cancer or other malignant diseases; (ii) a history of bilateral oophorectomy; (iii) suffering from memory problems; (iv) on long-term physical activity limitation. Subjects were initially screened using the hospital daily census sheets. All eligible inpatients had their diagnosis subsequently confirmed by histopathological reports to avoid misclassification, resulting in a 
final sample of 500 controls. No statistically significant differences were found between the included and excluded women in terms of age and main demographic variables.

An appointment for a 45 min face-to-face interview was arranged via nursing staff to avoid interference with treatment at the ward. Whenever possible, subjects were interviewed in the presence of their next-of-kin to minimize recall error. All participants gave formal consent. Each interview, conducted by the second author in either Mandarin or the Cantonese dialect, took about 45 minutes to complete. The project protocol was approved by the participating hospitals and Curtin University Human Research Ethics Committee.

A structured questionnaire was administered to obtain demographic and lifestyle characteristics, reproductive history, hormonal status and heredity. Information on habitual physical activity, including occupational, household, commuting and recreational activities, was solicited (Jian et al., 2005). Participants reported the average number of hours engaging in strenuous sports, vigorous work, and moderate activity. The intensity classification was based on the amount of energy or effort a person expends in performing the activity. A reference recall period was set at 5 years before interview. The habitual physical activity thus reflected the period when the subjects were generally healthy.

Physical activity exposure at each intensity level was quantified in terms of metabolic equivalent tasks (MET)-hours per week. Following the standard scoring mechanism for older Chinese women (Zhang et al., 2003), intensity codes 7.5, 6.0 and 4.5 MET were assigned for strenuous sports, vigorous work and moderate activity, respectively, regardless of the actual age. Total physical activity exposure was calculated by summing the product of MET score and activity duration over the three intensity levels. Sitting duration in both occupational- and leisure-time was assessed by number of hours in a day sitting at work, while watching television, in car or bus, at meals, and in other activities (Zhang et al., 2004). Total sitting duration was obtained by summing the hours spent in all sitting activities.

Unconditional logistic regression analyses were performed to ascertain the association between habitual physical activity and the ovarian cancer risk. Each physical activity variable was classified into 3 increasing levels of exposure, with zero (no engagement) taken as the reference category for strenuous sports, vigorous work and moderate activity. The effect of sedentary exposure was investigated in a separate model, with sitting duration categorized as 
low ( $\leq 4$ hours/day), moderate ( 4.5 to 8 hours/day), and high ( $\geq 8.5$ hours/day) levels based on the distribution of controls.

\section{RESULTS}

As shown in Table 1, the case and control groups appeared similar with respect to demographic and lifestyle factors. However, cases tended to have less oral contraceptive use and lower parities but higher mean body mass index than controls. The low prevalence of strenuous sports engagement was expected for these older women. Fewer cases participated in strenuous sports and vigorous work and generally they had lower levels of physical activity exposure when compared with the controls. There was no significant difference in total sitting duration between the two groups.

Table 2 presents the logistic regression results. Significant inverse association with the ovarian cancer incidence was evident for strenuous sports and moderate activity but not vigorous work. For total physical activity exposure, the ovarian cancer risk reduced to half for engaging in 23 or more MET-hours relative to less than 12 MET-hours per week. The corresponding dose-response relationship was also significant. However, the slight increase in cancer risk for a longer sitting duration did not attain statistical significance.

\section{DISCUSSION}

An inverse association was found between habitual physical activity and ovarian cancer risk in southern Chinese women. Both occupational and leisure time activity levels were measured using a validated and reliable instrument (Jian et al., 2005). Another strength was the implementation of a standardized identification procedure which ensured that ascertainment of cases was maximized and complete. To avoid misclassification of the casecontrol status, we recruited only incident patients diagnosed within the past 12 months.

Total physical activity in daily life was found to be associated with a lower ovarian cancer risk in this southern China population. The risk also reduced significantly for higher exposure to leisure time (strenuous sport and moderate) activities but to a lesser extent vigorous work. The majority of Chinese women were involved in occupations requiring intensive labour before the 1980s, and exposed to a high level of vigorous work when they were young. The results are consistent with our previous study in Hangzhou (Zhang et al., 2003) and provide further evidence to support findings from other countries (Carnide et al., 2009; Moorman et 
al., 2011; Rossing et al., 2010). A positive association with total sitting duration was also observed though the relation was not statistically significant. The finding is comparable with the marginal increase in risk among women in Hangzhou (Zhang et al., 2004).

Several limitations should be considered. Assessment of physical activity was based on selfreport, with a reference period set at five years before interview to avoid reverse causation, but the responses might still incur some recall error. Face-to-face interviews were thus conducted in the presence of their next-of-kin to help recall and to improve accuracy. Recruitment bias was minimized by sampling from different hospitals. Selection bias was unavoidable because all participants were voluntary. Nevertheless, the hospitals serve the entire catchment region; hence our subjects were representative of the target population. Information bias was unlikely because all participants were blinded to the study hypothesis. Finally, residual confounding might still exist even though established risk factors have been controlled for in the multivariable analyses.

\section{CONCLUSION}

Habitual physical activity was inversely associated with ovarian cancer risk among southern Chinese women. Physical activity is a modifiable lifestyle factor. Leisure time exercise activities should be further promoted and encouraged among women because of the potential benefit in ovarian cancer prevention.

\section{Conflict of Interest Statement}

The authors declare that there are no conflicts of interest. 


\section{REFERENCES}

Carnide N, Kreiger N, Cotterchio M, 2009. Association between frequency and intensity of recreational physical activity and epithelial ovarian cancer risk by age period. Eur $\mathbf{J}$ Cancer Prev 18: 322-330.

Ferlay J, Shin H, Bray F, Forman D, Mathers C, Parkin D, 2010. Cancer Incidence and Mortality Worldwide. Lyon, France: International Agency for Research on Cancer. http://globocan.iarc.fr [Accessed 25 April 2012].

Jian L, Shen ZJ, Lee AH, Binns CW, 2005. Moderate physical activity and prostate cancer risk: a case-control study in China. Eur J Epidemiol 20: 155-160.

Moorman PG, Jones LW, Akushevich L, Schildkraut JM, 2011. Recreational physical activity and ovarian cancer risk and survival. Ann Epidemiol 21: 178-187.

Rossing MA, Cushing-Haugen KL, Wicklund KG, Doherty JA, Weiss NS, 2010.

Recreational physical activity and risk of epithelial ovarian cancer. Cancer Causes Control 21: 485-491.

Sankaranarayanan R, Ferlay J, 2006. Worldwide burden of gynaecological cancer: the size of the problem. Best Pract Res Clin Obstet Gynaecol 20: 207-225.

Sueblinvong T, Carney ME, 2009. Current understanding of risk factors for ovarian cancer. Curr Treat Options Oncol 10: 67-81.

Zhang M, Lee AH, Binns CW, 2003. Physical activity and epithelial ovarian cancer risk: a case-control study in China. Int J Cancer 105: 838-843.

Zhang M, Xie X, Lee AH, Binns CW, 2004. Sedentary behaviours and epithelial ovarian cancer risk. Cancer Causes Control 15: 83-89. 
Table 1. Characteristics of southern Chinese women with and without ovarian cancer in Guangzhou, 2006-2008

\begin{tabular}{|c|c|c|c|c|c|}
\hline \multirow[t]{2}{*}{ Variable } & \multicolumn{2}{|c|}{ Cases } & \multicolumn{2}{|c|}{ Controls } & \multirow[b]{2}{*}{$\mathrm{p}^{\mathrm{a}}$} \\
\hline & $\mathrm{n}$ & $(\%)$ & $\mathrm{n}$ & $(\%)$ & \\
\hline Age at interview (years): mean (SD) & 59.07 & (5.68) & 59.7 & (6.46) & 0.10 \\
\hline Body Mass Index (5 years ago, $\left.\mathrm{kg} / \mathrm{m}^{2}\right)$ : mean (SD) & 21.70 & $(2.54)$ & 21.1 & $(2.28)$ & $<0.01$ \\
\hline Location of residence & & & & & 0.32 \\
\hline Urban & 362 & $(72.4)$ & 375 & $(75.0)$ & \\
\hline Rural & 138 & $(27.6)$ & 124 & $(24.8)$ & \\
\hline Employment status & & & & & 0.69 \\
\hline Unemployed/housewife & 163 & $(32.6)$ & 169 & $(33.8)$ & \\
\hline Working & 337 & $(67.4)$ & 331 & $(66.2)$ & \\
\hline Education level & & & & & 0.90 \\
\hline None/primary & 204 & $(40.8)$ & 197 & $(39.4)$ & \\
\hline Secondary & 171 & $(34.2)$ & 175 & $(35.0)$ & \\
\hline Tertiary & 125 & $(25.0)$ & 128 & $(25.6)$ & \\
\hline Tobacco smoking & & & & & 0.49 \\
\hline Never & 481 & $(96.2)$ & 485 & $(97.0)$ & \\
\hline Ever & 19 & $(3.8)$ & 15 & $(3.0)$ & \\
\hline Alcohol drinking & & & & & 0.16 \\
\hline No & 352 & $(70.4)$ & 372 & $(74.4)$ & \\
\hline Yes & 148 & $(29.6)$ & 128 & $(25.6)$ & \\
\hline Marital status & & & & & 0.83 \\
\hline Never married & 7 & $(1.4)$ & 8 & $(1.6)$ & \\
\hline Married & 449 & $(89.8)$ & 443 & $(88.6)$ & \\
\hline Widowed/divorced/separated & 44 & $(8.8)$ & 49 & $(9.8)$ & \\
\hline Parity & & & & & $<0.01$ \\
\hline 0 & 8 & $(1.6)$ & 14 & $(2.8)$ & \\
\hline 1 & 172 & $(34.4)$ & 143 & $(28.6)$ & \\
\hline 2 & 219 & $(43.8)$ & 176 & $(35.2)$ & \\
\hline$\geq 3$ & 101 & $(20.2)$ & 167 & $(33.4)$ & \\
\hline Oral contraceptive use & & & & & $<0.01$ \\
\hline No & 417 & $(83.4)$ & 380 & $(76.0)$ & \\
\hline Yes & 83 & $(16.6)$ & 120 & $(24.0)$ & \\
\hline Hormone replacement therapy & & & & & 1.00 \\
\hline No & 493 & $(98.6)$ & 493 & $(98.6)$ & \\
\hline Yes & 7 & $(1.4)$ & 7 & $(1.4)$ & \\
\hline Menopausal status & & & & & 0.24 \\
\hline Pre & 28 & $(5.6)$ & 20 & $(4.0)$ & \\
\hline Post & 472 & $(94.4)$ & 480 & $(96.0)$ & \\
\hline Hysterectomy & & & & & 0.88 \\
\hline No & 478 & $(95.6)$ & 477 & $(95.4)$ & \\
\hline Yes & 22 & $(4.4)$ & 23 & $(4.6)$ & \\
\hline Ovarian cancer in first degree relatives & & & & & 0.29 \\
\hline No & 486 & $(97.2)$ & 491 & $(98.2)$ & \\
\hline Yes & 14 & $(2.8)$ & 9 & $(1.8)$ & \\
\hline Breast cancer in first degree relatives & & & & & 1.00 \\
\hline No & 494 & $(98.8)$ & 494 & $(98.8)$ & \\
\hline Yes & 6 & $(1.2)$ & 6 & $(1.2)$ & \\
\hline
\end{tabular}


Strenuous sports

(MET-hours/week): mean (SD)

Vigorous work

(MET-hours/week): mean (SD)

Moderate activity

(MET-hours/week): mean (SD)

Total physical activity

(MET-hours/week): mean (SD)

Sitting

(hours/day): mean (SD) $\begin{array}{llll}47 & (9.4) \quad 72 & (14.4)\end{array}$

$\begin{array}{lll}0.63(2.3) & 0.99(2.8) & 0.03\end{array}$

$\begin{array}{llll}133 & (26.6) & 167 & (33.4)\end{array}$

$2.64(7.0) \quad 3.01(5.4) \quad 0.35$

$\begin{array}{llll}497 & (99.4) & 499 & (99.8)\end{array}$

$12.93(12.2) \quad 14.84(11.5) \quad 0.01$

$16.21(14.1) \quad 18.84(13.0) \quad<0.01$

$7.16(4.2) \quad 6.91(4.3)$

${ }^{a}$ chisquare or t-test for difference between cases and controls 
Table 2. Crude and adjusted odds ratios (OR, 95\% confidence intervals) of ovarian cancer risk for physical activity in southern Chinese women, 2006-2008

\begin{tabular}{|c|c|c|c|c|c|}
\hline Activity & $\begin{array}{l}\text { Cases } \\
\mathrm{n}(\%)\end{array}$ & $\begin{array}{c}\text { Controls } \\
\mathrm{n}(\%)\end{array}$ & $\begin{array}{c}\text { Crude OR } \\
(95 \% \text { CI })\end{array}$ & $\begin{array}{l}\text { Adjusted OR } \mathbf{O R}^{\mathrm{a}} \\
(95 \% \mathrm{CI})\end{array}$ & $\begin{array}{l}p \text { for } \\
\text { trend }\end{array}$ \\
\hline $\begin{array}{l}\text { Strenuous sports } \\
\text { (MET-hours/week) }\end{array}$ & & & & & 0.01 \\
\hline 0 & $\begin{array}{c}453 \\
(90.6)\end{array}$ & $\begin{array}{c}428 \\
(85.6)\end{array}$ & 1.00 & 1.00 & \\
\hline$<6$ & $\begin{array}{c}43 \\
(8.6)\end{array}$ & $\begin{array}{c}65 \\
(13.0)\end{array}$ & $\begin{array}{c}0.63 \\
(0.42-0.94)\end{array}$ & $\begin{array}{c}0.58 \\
(0.38-0.88)\end{array}$ & \\
\hline$\geq 6$ & $\begin{array}{c}4 \\
(0.8)\end{array}$ & $\begin{array}{c}7 \\
(1.4)\end{array}$ & $\begin{array}{c}0.54 \\
(0.16-1.86)\end{array}$ & $\begin{array}{c}0.40 \\
(0.11-1.44)\end{array}$ & \\
\hline $\begin{array}{l}\text { Vigorous work } \\
\text { (MET-hours/week) }\end{array}$ & & & & & 0.79 \\
\hline 0 & $\begin{array}{c}367 \\
(73.4)\end{array}$ & $\begin{array}{c}333 \\
(66.6)\end{array}$ & 1.00 & 1.00 & \\
\hline$<5$ & $\begin{array}{c}85 \\
(17.0)\end{array}$ & $\begin{array}{c}98 \\
(19.6)\end{array}$ & $\begin{array}{c}0.79 \\
(0.57-1.09)\end{array}$ & $\begin{array}{c}0.89 \\
(0.63-1.25)\end{array}$ & \\
\hline$\geq 5$ & $\begin{array}{c}48 \\
(9.6)\end{array}$ & $\begin{array}{c}69 \\
(13.8)\end{array}$ & $\begin{array}{c}0.63 \\
(0.42-0.94)\end{array}$ & $\begin{array}{c}0.81 \\
(0.53-1.25)\end{array}$ & \\
\hline $\begin{array}{l}\text { Moderate activity } \\
\text { (MET-hours/week) }\end{array}$ & & & & & 0.02 \\
\hline 0 & $\begin{array}{c}3 \\
(0.6)\end{array}$ & $\begin{array}{c}1 \\
(0.2)\end{array}$ & 1.00 & 1.00 & \\
\hline$<11.5$ & $\begin{array}{c}370 \\
(74.0)\end{array}$ & $\begin{array}{c}333 \\
(66.6)\end{array}$ & $\begin{array}{c}0.37 \\
(0.04-3.58)\end{array}$ & $\begin{array}{c}0.14 \\
(0.01-1.53)\end{array}$ & \\
\hline$\geq 11.5$ & $\begin{array}{c}127 \\
(25.4)\end{array}$ & $\begin{array}{c}166 \\
(33.2) \\
\end{array}$ & $\begin{array}{c}0.57 \\
(0.03-2.48)\end{array}$ & $\begin{array}{c}0.10 \\
(0.01-1.06)\end{array}$ & \\
\hline $\begin{array}{l}\text { Total physical activity } \\
\text { (MET-hours/week) }\end{array}$ & & & & & 0.02 \\
\hline$<12$ & $\begin{array}{c}287 \\
(57.4)\end{array}$ & $\begin{array}{c}226 \\
(45.2)\end{array}$ & 1.00 & 1.00 & \\
\hline $12-22$ & $\begin{array}{c}133 \\
(26.6)\end{array}$ & $\begin{array}{c}133 \\
(26.6)\end{array}$ & $\begin{array}{c}0.79 \\
(0.59-1.06)\end{array}$ & $\begin{array}{c}0.82 \\
(0.60-1.11)\end{array}$ & \\
\hline$\geq 23$ & $\begin{array}{c}80 \\
(16.0)\end{array}$ & $\begin{array}{c}141 \\
(28.2)\end{array}$ & $\begin{array}{c}0.45 \\
(0.32-0.62)\end{array}$ & $\begin{array}{c}0.49 \\
(0.35-0.68)\end{array}$ & \\
\hline $\begin{array}{l}\text { Sitting } \\
\text { (hours/day) }\end{array}$ & & & & & 0.94 \\
\hline$\leq 4$ & $\begin{array}{c}159 \\
(31.8)\end{array}$ & $\begin{array}{c}175 \\
(35.0)\end{array}$ & 1.00 & 1.00 & \\
\hline $4.5-8$ & $\begin{array}{c}152 \\
(30.4)\end{array}$ & $\begin{array}{c}156 \\
(31.2)\end{array}$ & $\begin{array}{c}1.07 \\
(0.79-1.46)\end{array}$ & $\begin{array}{c}1.01 \\
(0.73-1.41)\end{array}$ & \\
\hline$\geq 8.5$ & $\begin{array}{c}189 \\
(37.8)\end{array}$ & $\begin{array}{c}169 \\
(33.8)\end{array}$ & $\begin{array}{c}1.23 \\
(0.91-1.66)\end{array}$ & $\begin{array}{c}1.07 \\
(0.77-1.48)\end{array}$ & \\
\hline
\end{tabular}

${ }^{a}$ Estimates from separate logistic regression models adjusting for age (years), parity, oral contraceptive use (never, ever), body mass index (5 years ago), menopausal status (pre, post), education level (none/primary, secondary, tertiary), smoking status (never, ever), family history of ovarian or breast cancer (no, yes). 